\title{
LA ORDEN MILITAR DE ALCÁNTARA Y LA MONARQUÍA CASTELLANA DURANTE LOS PRIMEROS TRASTÁMARAS \\ (1369-1390)
}

\author{
FELICIANO NOVOA PORTELA ${ }^{1}$
}

\begin{abstract}
Resumen: Este artículo trata de analizar las relaciones de la Orden de Alcántara con los dos primeros reyes de la dinastia Trastamara, concretamente, con Enrique II y Juan I. Durante este período, la Orden sufre un cambio sustancial que se traduce, por una parte, en el fin de su política equívoca con la Corona castellana y, por otra, en la disminución de su autonomía institucional, que tiene su elemento más significativo en el control de la designación de sus Maestres. Todo este proceso se situa en una política desarrollada por los dos soberanos cuyo objetivo era reforzar el poder real y el aumento progresivo en manos de la Corona de medios y de atribuciones políticas.

Palabras clave: Órdenes Militares; Orden de Alcántara; Enrique I de Castilla; Juan I de Castilla; Portugal; Frontera.
\end{abstract}

Abstract: This work tries to analyze the relations of Alcántara's order with the first two kings of the of dynasty Trastámara, concretly with Enrique II and Juan I. During this period, the Order will suffer a substantial change that is translated, on the one hand, in the purpose of his equivocal politics with the Castilian rown and, for other one, in the decrease of his institutional autonomy that has in the control of the appointment of the masters for his element more significant. All this process places inside a politics led to end for both monarches, whose aim was going to strengthen the power royal and to a progressive increase of means and of political attributions in hands of the monarchie.

Keywords: Military Orders; Order of Alcantara; Enrique II of Castile; Juan I of Castile; Portugal; Frontier.

${ }^{1}$ Técnico de Museos, Museo Arqueológico Nacional. Madrid. 2004.

Fecha de recepción del artículo: septiembre 2003. Fecha de aceptación y versión final: enero

«Anuario de Estudios Medievales», 34/1 (2004), pp.79-98 .- ISSN 0066-5061. 


\section{SUMARIO}

Planteamiento.- I. El enfrentamiento entre las Coronas de Castilla y Portugal: el proceso de "nacionalización" de la Orden de Alcántara.- II. El control del nombramiento del cargo del maestre por parte de la Corona.- III. Las donaciones reales a la Orden.- IV. La confirmación del patrimonio de la Orden por la Corona.- Conclusiones.

\section{Planteamiento}

El nacimiento de la orden de San Julián del Pereiro (segunda mitad del siglo XII), más adelante llamada de Alcántara, estuvo relacionado con las necesidades de la monarquía leonesa de crear y consolidar un espacio que le asegurara su expansión hacia el sur, pero también y sobre todo con el objetivo de colonizar unos territorios, el Ribacôa y el occidente de la llamada Transierra leonesa, lugares de origen y de expansión de la milicia extremeña, que se convirtieron en objeto de fuertes enfrentamientos entre las coronas portuguesa y castellana-leonesa, hasta finales del siglo XIV.

En estas disputas, la milicia extremeña tuvo un papel protagonista pero, al contrario de lo que podía pensarse, su política tuvo casi siempre un carácter vacilante debido, por un lado, a los intereses territoriales y económicos que llegó a adquirir en territorio portugués ${ }^{2}$ y, por el otro, a su resistencia a un proceso de centralización y reafirmación monárquica que tuvo sus orígenes en los planteamientos políticos de Alfonso X $(1252-1284)^{3}$ y cuya característica más importante, en lo referente a las órdenes militares, era el interés de la monarquía por controlar absolutamente estas instituciones. A estos dos elementos habría que añadir un tercero: los territorios y la población alcantarina estaban, en su mayoría, más cercanos a la realidad socioeconómica portuguesa que a la castellana $\mathrm{o}$, dicho con otras palabras, no

${ }^{2}$ F. NovoA Portela, La Orden de Alcántara y Extremadura (siglos XII-XIV), Mérida, Editora Regional de Extremadura, 2000, pp. 146-153.

${ }^{3}$ Algunos autores han visto en este proceso la génesis del Estado Moderno. Sobre la cuestión, es recomendable y bastante clarificadora la introducción que hace el profesor NIETO SORIA en su libro Iglesia y génesis del Estado Moderno en Castilla (1369-1480), 1993, pp. 17-40. Con anterioridad, J.R. STRAYER analizó, aunque solo para Francia e Inglaterra, esos mismos antecedentes de lo que llama Estado Moderno (Sobre los orígenes medievales del Estado moderno, Barcelona, 1981).

«Anuario de Estudios Medievales», 34/1 (2004), pp.79-98 .- ISSN 0066-5061. 
existía en esa zona lo que, en términos modernos, podríamos llamar "una identidad castellano-leonesa"4.

Esa política de titubeo tuvo un claro ejemplo durante el reinado de Alfonso XI, concretamente entre 1336-1339, años de conflicto con Portugal, que se saldó, en lo referente a la Orden de Alcántara, con la sustitución del maestre Rodrigo Pérez Maldonado debido a su actitud poco convincente en el rechazo a las tropas portuguesas y con la muerte, con posterioridad, del también maestre Gonzalo Martínez de Oviedo, aliado en su rebeldía del rey portugués. En este caso, como en muchos otros, la Orden sufrió una injerencia directa por parte de la Corona que produjo fuertes divisiones de difícil solución y con ellas el "exilio" en Portugal de buena parte de sus efectivos ${ }^{5}$.

El objetivo de estas páginas es precisamente analizar las relaciones de la Orden, en éste y en otros aspectos, con la nueva dinastía Trastámara, concretamente con sus dos primeros titulares, Enrique II y Juan I, dos monarcas que continuaron el proceso ya aludido de fortalecimiento de la monarquía ${ }^{6}$, aunque, eso sí, con características diferentes que acabaron por otorgar un perfil muy determinado a este periodo y que, en lo relativo a la orden de Alcántara abrieron el camino a su definitiva "soberanización" y posterior incorporación a la Corona.

${ }^{4}$ J.L. MARTín MARTíN señala que Portugal tenía más intereses y ejercía un mayor y mejor control sobre los territorios fronterizos (Conflictos luso-castellanos por la Raya en "Revista da Facultade de Letras-Historia, II Serie, vol. XV, Porto (1998), p. 261. También la política portuguesa se adecuó mucho mejor a lo que Carlos de AYALA ha llamado postulados secularizantes de la realeza [portuguesa] defendiendo de este modo su autonomía frente al reino castellano, en el que radicaban sus referencias disciplinarias más o menos inmediatas (Las órdenes militares hispánicas en la Edad Media (siglos XII-XV), 2003, p. 725).

${ }^{5}$ Sobre estos y otros ejemplos, ver nuestro trabajo Los maestres de la Orden de Alcántara durante los reinados de Alfonso XI y Pedro I, en "Historia. Instituciones y Documentos", 29 (2002), pp. 317-335.

${ }^{6} \mathrm{El}$ profesor Julio Valdeón ha insistido en numerosas publicaciones sobre la labor centralizadora de Enrique II y los primeros Trastámaras, no encontrando "contradicción entre el objetivo de fortalecer a la monarquía, por una parte, y la abundante concesión de mercedes a la nobleza, de la que fue protagonista Enrique II". En síntesis, al resumir los rasgos más significativos del gobierno de los Trastámara, señala que uno de ellos, el primero, era el fortalecimiento de la autoridad de la monarquía. El otro se refería al papel hegemónico que adquirió la Corona de Castilla en el conjunto de las tierras hispánicas (Pedro I el Cruel y Enrique de Trastámara ¿La primera guerra civil española?, 2002, p. 275. Otras obras de este autor sobre el mismo tema: La victoria de Enrique II: Los Trastámaras en el poder en "Génesis medieval del Estado Moderno: Castilla y Navarra (1250-1370)", Valladolid, 1987: Enrique II de Castilla: la guerra civil y la consolidación del régimen (1366-1371), Valladolid, 1966; Enrique II. 13691379, Palencia, 1996; Los Trastámaras. Un triunfo de una dinastía bastarda, Madrid, 2001.

«Anuario de Estudios Medievales», 34/1 (2004), pp.79-98 .- ISSN 0066-5061. 


\section{EL ENFRENTAMIENTO \\ ENTRE LAS CORONAS DE CASTILlA Y PORTUGAL: \\ EL PROCESO DE "NACIONALIZACIÓN" \\ DE LA ORDEN DE ALCÁNTARA}

En la primavera de 1369, se produjo en los campos de Montiel la derrota y muerte del rey Pedro I y el inicio de una nueva dinastía. Pero la victoria, como ocurre tantas veces, no trajo inmediatamente la paz. Para eso habría que esperar dos años más, hasta el año 1371, cuando acontecen dos importantes hechos que simbolizan la consolidación de la dinastía trastámara: las paces de Alcoutim con Portugal y las Cortes de Toro. También en la historia particular de la Orden de Alcántara, esos años constituyeron un momento crucial, en cierto modo paralelo al del reino: el que va desde la división y el enfrentamiento interno hasta la concordia y la paz. A esos años, el profesor Valdeón los ha calificado con razón como "años cruciales"

Una las primeras medidas que tomó Enrique II al inicio de su reinado, utilizando este término en el sentido pleno, es decir después de la batalla de Montiel en marzo de $1369^{7}$, fue la elección de un nuevo maestre de Alcántara, responsabilidad que recayó en el clavero Melen Suárez $z^{8}$, un fiel seguidor de Enrique II desde el principio de la rebelión enriqueña ${ }^{9}$, que había intervenido en las batallas de Nájera, donde cayó prisionero de los petristas, y de Montiel y que, en los últimos tiempos de la contienda, ya había ejercido el cargo de administrador legal de la Orden por decisión papal ${ }^{10}$. Sobre el interés del Rey para que saliera elegido valgan las palabras del cronista alcantarino Torres y Tapia: convinieronse en darle gusto [al rey] y hacer lo que les mandaba, por

${ }^{7}$ Recordemos que su elección había tenido lugar en el monasterio burgalés de las Huelgas en abril de 1366.

${ }^{8}$ No es mucho lo que sabemos sobre la ascendencia familiar del nuevo maestre. Solamente Torres y Tapia, el cronista de la Orden, nos señala: no se sabe más que decir fue de los de Sotomayor (Crónica de la Orden de Alcántara, Madrid, 1763, II, p. 124)

${ }^{9} \mathrm{El}$ nuevo maestre había estado presente, en el bando trastamarista, en hechos tan señalados como Calahorra y Nájera (P. LóPEZ DE AYALA, Crónica del Rey Don Pedro, Biblioteca de Autores Españoles, t. LXVI, Madrid, 1953, pp. 400 y 552.

${ }^{10}$ Sobre los avatares de su nombramiento ver nuestro trabajo, Los maestres de la Orden de Alcántara durante los reinados de Alfonso XI y Pedro I, p. 329 y ss.

«Anuario de Estudios Medievales», 34/1 (2004), pp.79-98 .- ISSN 0066-5061. 
lo mucho que la Orden interesaba en tenerle propicio, y que el habia de arrimar el hombro y sacar por Maestre al Clavero como quiera que fuese ${ }^{11}$.

Pero solamente tres meses después, cuando aún no había acabado la primavera de 1369, concretamente en el mes junio, el nuevo maestre había abandonado de forma sorprendente las filas reales para dar su apoyo a las pretensiones de Fernando I de Portugal que aspiraba a coronarse rey de Castilla y León en nombre de un legitimismo que el rey portugués afirmaba representar. El mismo objetivo perseguían los antiguos petristas que aún resistían en algunas zonas del reino, como Galicia, Zamora, Ciudad Rodrigo y Carmona, lugar este último donde se encontraba atrincherado el antiguo maestre de Alcántara y Calatrava y devoto seguidor petrista, Martín López de Córdoba. Aún así, conviene precisar que, en principio, ambas cuestiones, el apoyo a las pretensiones del rey portugués y el acercamiento a los seguidores del rey Pedro, eran diferentes para el maestre alcantarino, aunque los fines de uno y otros coincidieran ¿Cuales fueron pues las razones que llevaron al maestre alcantarino a tal cambio?. Desde luego, repetimos, no tuvo nada que ver con un reconocimiento tardío, por parte de Melen Suárez, de la legitimidad petrista, sino más bien con los intereses generales de la Orden que cambiaron radicalmente una vez que Fernando I de Portugal manifestó su intención de ocupar el trono castellano-leonés, aunque el verdadero propósito del rey portugués fuera alargar o pequenho Portugal para poder contrabalançar o poderío de Castela, sempre ameaçador, tácita o explicitamente ${ }^{12}$. Y así lo hizo al "ocupar" los territorios fronterizos pertenecientes a la Orden de Alcántara, unos territorios cuyas villas más importantes -Alcamtara, Vallença Dalcantara... - habían alzado, desde el principio, su voz a favor del rey portugués ${ }^{13}$.

\footnotetext{
${ }^{11}$ Crónica de Alcántara, II, p. 125.

${ }^{12}$ Introducción del profesor Salvador Dias Arnaut a la Crónica do senhor rei Dom Fernando Nono rei desdes regnos de FERNÃo LOPES, Porto, 1966, p. XXII = LOPES CFI. También C. de Ayala y F.J. Villalba Ruiz de Toledo insisten en que la verdadera intención de Fernando I era una ampliación territorial de su reino a costa del ilegítimo monarca castellano (Procedentes lejanos de la crisis de 1383: Circunstancias políticas que acompañan al tratado de Santarem en "Actas das II Jornadas Luso-Espanholas de Histórica Medieval", Porto, 1987, p. 235).

${ }^{13}$ Recordemos que los dos reinos habían dado una solución a sus problemas fronterizos en el tratado de Alcañices de 1297, aunque para Portugal continuaba siendo un objetivo primordial engrandecer su territorio a costa del reino castellano -Portugal ya solo tenía, en estos momentos, una única frontera- $\mathrm{y}$, consiguientemente, un motivo de pugna constante entre los dos reinos con claras implicaciones jurisdiccionales.
}

«Anuario de Estudios Medievales», 34/1 (2004), pp.79-98 .- ISSN 0066-5061. 
La "ocupación" tenía voluntad de ser definitiva o, dicho de otra forma, se intentaba, por la vía de los hechos consumados, redefinir una nueva frontera: esto parece confirmarse si nos atenemos al contenido de la Crónica de Fernao Lópes - sabee que non foi levemente assi tomada, que el nom husasse em ellas de todo poderio, como nos outros logares de seu reino- y a las numerosas medidas, entre ellas la emisión de moneda que en varios ciudades, como las citadas de Alcántara y Valencia de Alcántara, mandou fazer como Rei e senhor natural ${ }^{14}$.

Probablemente es inadecuada la utilización del término "ocupación", primero, porque no parece que se hubiera producido una invasión territorial como tal $\mathrm{y}$, en segundo lugar, porque tal hecho era innecesario en unos territorios que estaban, en su mayoría, como ya hemos dicho, más cercanos a la realidad portuguesa que a la castellano-leonesa. A esto habría que añadir que Enrique II se encontraba en una posición cuando menos delicada debido a los numerosos frentes abiertos, Navarra, Aragón y Granada, que hacían pensar que las reivindicaciones territoriales portuguesas, no solamente eran posibles, sino probables.

En ese marco es donde encontramos explicación al que puede parecer en principio sorprendente cambio de lealtad del maestre alcantarino, pero que no era otra cosa, ya lo hemos dicho, que la defensa de unos intereses económicos y políticos que estaban íntimamente relacionados con los territorios objeto de disputa: no olvidemos que la mayoría de las posesiones de la Orden se circunscribían a la actual región de Extremadura y dentro de ella a la zona de lo que con posterioridad se llamó el Partido de Alcántara. Fuera de estos territorios, los bienes alcantarinos nunca fueron excesivamente significativos.

La toma de posición de la gran mayoría de la Orden de Alcántara se concretó en un conjunto de acciones, que tenía como objetivo establecer una relación definitiva con el reino de Portugal. La primera de estas medidas, de carácter netamente interno, fue el nombramiento de un tal Ruy Vaez de Casteloblanco como Comendador Mayor, lo que significaba, teniendo en cuenta que ese cargo era generalmente el último escalón antes de acceder al

${ }^{14}$ F. LOPES, CFI, cap. XXVIII, p. 81.

«Anuario de Estudios Medievales», 34/1 (2004), pp.79-98 .- ISSN 0066-5061. 
maestrazgo de la Orden ${ }^{15}$, que el próximo maestre sería posiblemente portugués ${ }^{16}$.

Otras acciones, éstas de carácter militar, tienen que ver con la participación de la Orden en la ofensiva militar que Fernando I llevó a cabo desde los primeros días del mes de junio de 1369. A la entrada en Galicia, el 15 de junio, y al envío de una flota con el objetivo de bloquear el río Guadalquivir, habría que unir las operaciones militares que llevó a cabo el maestre alcantarino para asegurar que la Orden, sus territorios y sus fortalezas continuaran al lado del rey portugués. La crónica de Torres y Tapia es clara en este sentido: el maestre Melen Suárez reduce, en estos primeros días del mes de junio, a los que se habian apartado de el y favorecían el partido del Rey. D. Enrique. Estos freires "castellanistas", cuyo caudillo era el clavero D. Diego Martínez, se habían refugiado en el castillo de Peñafiel, cercano a la frontera portuguesa del que terminaron por ser desalojados ${ }^{17}$. A continuación, la Crónica nos relata como el maestre prosiguió su labor de control visitando diferentes fortalezas que estaban en la frontera de su Reyno, que eran Santibáñez, los Eljas, Salvaleón, la Torre de Almenara, y parece dio vuelta a Alcántara para proseguir por Valencia, Mayorga, Herrera y Esparragal, que todas estaban ya en poder de Canballeros que seguían la voz del Rey de Portogal ${ }^{18}$.

No se limitó la labor de Melen Suárez al mero control militar de su territorio, puesto que sabemos que un año más tarde, en junio de 1370, se encontraba en Zafra ${ }^{19}$ para, si así lo decidía el rey de Portugal, prestar su ayuda a la villa de Carmona donde se encontraba cercado Martín López de Córdoba por las tropas de Enrique II: ir en persona si el Rey. D. Fernando

${ }^{15}$ Ver nuestro trabajo Algunas consideraciones sobre los maestres de la Orden de Alcántara desde su nacimiento hasta 1350, en "Revista de Estudios Extremeños" (en prensa).

${ }^{16}$ Torres y Tapia nos dice que no fue bien recibido por Comendador Mayor y asi se ha de tener por intruso (Crónica, t. II, p. 130). Por su parte, el cronista Fernão Lopes señala que el rey Fernando I ordenó a la Orden que tuviese por logoteemte do mestre dessa hordem, García Pérez do Campo craveiro (cap. XXVIII, p. 82).

${ }^{17}$ Sobre el cerco, tenemos noticias gracias a un documento de ocho de junio de 1369 realizado en el Real sobre Peñafiel. Se trata de un documento en el que el maestre confirma su fuero al concejo de Zalamea (Crónica, t. II, p. 127).

${ }^{18}$ Ibídem, t. II, p. 128.

${ }^{19} \mathrm{El}$ maestre Melen Suárez ordena que se suprima la fijación de los productos alimenticios ordenada anteriormente en Zafra y asimismo establece algunas normas relativas a los salarios y beneficios de los alcaldes de la villa (B. PALACIOS MARTín (Ed.), Colección diplomática medieval de la Orden de Alcántara (1157?-1494), t. I, De los origenes a 1454, Madrid (2001) = PALACIOS, Colección de Alcántara, I doc. 673, pp. 465-466).

«Anuario de Estudios Medievales», 34/1 (2004), pp.79-98 .- ISSN 0066-5061. 
de Portugal resolviese de inviar gente de guerra. No se llevó a cabo tal acción aunque se le hizo harto esfuerzo por D. Martín López y los que estaban con el en Carmona ${ }^{20}$

En cualquier caso, en estos momentos, mediados de 1370, la posición de Enrique II se vio agravada por la alianza anticastellana de Portugal y Aragón, por la persistencia de los focos petristas en el interior de Castilla y finalmente por la marcha de las tropas mercenarias del famoso du Guesclin. Sin embargo poco tiempo después, entrado el verano, la situación iba a cambiar de forma radical debido a una serie de importantes acontecimientos que hicieron posible que el rey castellano rompiera el cerco "político y militar" al que estaba sometido: las treguas con otros reinos hispanos, como Granada $^{21}$ y Navarra, la incomprensible inactividad militar de Aragón, el desbloqueo del río Guadalquivir en agosto y sobre todo por las aspiraciones al trono de Castilla de Juan de Gante, casado con Constanza, hija de Pedro I, que influyó decisivamente en la mengua del entusiasmo del rey portugués. Las consecuencias fueron nefastas para aquellos que desde Castilla abanderaban las pretensiones del rey portugués. Uno de ellos fue el maestre de Alcántara que vio como, a finales de 1370 , los freires castellanistas, al mando del citado Diego Martínez, tomaban la villa de Alcántara y le obligaban a pasarse a Portugal $^{22}$ : y se hiziesse processo contra él, por auer seguido al Rey de Portogal; y assi se hizo y fue priuador del Maestrazdgo ${ }^{23}$

El nombramiento del nuevo maestre, seguramente a principios del año siguiente ${ }^{24}$, se convirtió en un acto de afirmación real al imponer Enrique II a su candidato, el comendador mayor Ruy Díaz de la Vega, frente a Diego Martínez, clavero y al parecer preferido por la Orden. Es el cronista Rades

\footnotetext{
${ }^{20}$ Crónica, t. II, p. 129

${ }^{21}$ Ver el trabajo de J.E. LÓPEZ DE COCA CASTAÑER, Sobre las relaciones de Portugal con el reino de Granada (1369-1415), "Meridies. Revista de Historia Medieval", t. V-VI (2002), pp. 205-222.

${ }^{22}$ TORRES Y TAPIA, Crónica, t. II, p. 129

${ }^{23} \mathrm{~F}$. DE RADES y ANDRADA, Chronica de las Tres Ordenes y Cauallerías de Sanctiago, Calatraua y Alcántara, Toledo, 1572, ed. facs. Barcelona, 1980, Chronica de Alcántara, fol. 31.

${ }^{24}$ No sabemos exactamente la fecha de la destitución de Melen Suárez y nombramiento del nuevo maestre, puesto que ambos hechos tuvieron lugar al mismo tiempo: le depusiesen de la Dignidad Maestral, por haber negado la obediencia a su verdadero Rey y Señor Natural....y que procediesen á hacer elección de nuevo Maestre (Ibídem, t. II, p. 131). En cualquier caso en el mes de marzo tenemos constancia de que Ruy Díaz de la Vega ejercía como maestre: se trata de una confirmación al concejo de Gata del privilegio de exención de Santibáñez (PALACIOS, Colección de Alcántara, I, doc. nº 674, p. 466).
}

«Anuario de Estudios Medievales», 34/1 (2004), pp.79-98 .- ISSN 0066-5061. 
quien nos relata como la elección se había hecho no con toda libertad y en ausencia del nuevo maestre que estaba en Aragón como embajador del rey don Enrique $^{25}$.

La llegada a la dignidad maestral de Díaz de la Vega ${ }^{26}$ supuso la apuesta definitiva de la Orden de Alcántara por la causa trastamarista, como lo demuestra su presencia ${ }^{27}$ en las decisivas Cortes de Toro que constituyeron una excelente ocasión para asentar los cimientos del régimen trastamarista a través de numerosas confirmaciones de privilegios y de la regulación de diferentes estancias de la monarquía castellana: hacer y establecer leyes ${ }^{28}$. Por el contrario, no tenemos constancia de que Díaz de la Vega hubiera estado con anterioridad en Alcoutim, en marzo de 1371, donde las delegaciones lusocastellanas, con mediación pontificia, llegaron a un acuerdo que ponía fin al enfrentamiento entre los dos reinos y que contemplaba importantes modificaciones en ciertos bienes territoriales de la Orden. En concreto, el acuerdo preveía la cesión, entre otras, de la villa de Valencia de Alcántara, dentro de la dote que aportaba Leonor, hija de Enrique II, al matrimonio con el rey portugués: que el Rei Dom Fernamdo casasse con a Iffamte Dona Lionor filha del Rei Dom Hemrrique, con a qual ouvesse per doaçam en casamento, Çidade Rodrigo, e Vallemça Dalcamtara com todos seus termos, e Monte rei, e Alhariz com seus alfozes e fortallezas ${ }^{29}$.

Cabe preguntarse y así lo han hecho algunos autores, cómo fue posible que Enrique II hubiera accedido a modificar sus fronteras en unos momentos en que se encontraba en una teórica posición de fuerza respecto al rey portugués ${ }^{30}$, por lo menos parecía estarlo en los territorios de la Orden una vez que, como hemos visto, la milicia extremeña había quedado controlada

\footnotetext{
${ }^{25}$ RADES, Chronica de Alcántara, fol. 31.

${ }^{26}$ Según los cronistas Rades y Torres, el nuevo maestre era maestresala y muy privado del $r e i$, e hijo de Diego Laso de Vega y hermana de Elvira Iñíguez de la Vega que tubo el Rey en ella á D. Alonso que fue conde Gijón y de Noroña en Asturias que casó con D. Isabel hija del Rey D. Fernando de Portugal (Chrónica, fol. 31; Crónica de Alcántara, t. II, p. 132).

${ }^{27}$ Torres y Tapia da cuenta de la presencia del maestre en Toro, en septiembre de 1371 (Crónica, t. II, p. 133).

${ }^{28}$ Cortes de los antiguos reinos de León y Castilla, Madrid, 1861-1903, 3, p. 37

${ }^{29}$ LOPES, CFI, cap. LIII, p. 140.

${ }^{30}$ Diversos aspectos sobre esta cuestión han sido abordados por C. DE AYALA y F. J. Villalba RuIz DE TOLEDo (Precedentes lejanos de la crisis de 1383, p. 8) y V.A. AlvarEZ PALENZUELA, Las relaciones castellano-portuguesas en el panorama político internacional en V.A. Álvarez PAlenZuela (Ed.) "III Jornadas de Cultura Hispano-Portuguesa", 1999, p. 45.
}

«Anuario de Estudios Medievales», 34/1 (2004), pp.79-98 .- ISSN 0066-5061. 
por sus seguidores. No es fácil la respuesta y tampoco ese el objeto de análisis de estas páginas, pero sin duda la explicación hay que buscarla, no en uno, sino en varios factores como el deseo que tenía de gozar ya con quietud de sus Reynos $^{31}$ la política internacional de ambas monarquías y en el hecho, creo que importante, de que los lugares de Ciudad Rodrigo, Valencia de Alcántara, Allariz y Monterrey, continuaran alzados a favor del rey portugués en 1372, tiempo después del fracaso de los acuerdos de Alcoutim, lo que demostraba, por un lado el interés de estas poblaciones por continuar ligadas a la corona lusa, y, por el otro, la aún indefinición alcantarina: y que el rey Don Fernando le restituyese los Lugares que habian seguido su voz y todavía retenía ${ }^{32}$. No nos extraña, pues, que Fernando I terminara por romper los acuerdos de Alcoutim ya que contemplaban unas anexiones territoriales escasas y que además ya estaban a su lado y en su poder.

El siguiente paso que dio el monarca portugués en sus aspiraciones territoriales supuso un nuevo enfrentamiento con Enrique II: en julio de 1372 estableció acuerdos con el duque de Láncaster, pretendiente, como ya hemos dicho, a la corona castellana por estar casado con Constanza, la hija de Pedro I que había sido proclamada heredera de Castilla en la Cortes de Bubierca de 1363. La reacción castellana a la ofensiva anglo-portuguesa fue la entrada, a mediados del mes de diciembre de 1372, de las tropas de Enrique II, algunas de las cuales lo hicieron por territorios de la Orden, concretamente por Alcántara: e los caualleros e vasallos del rrey del Andalozia que auaian entrado por Alcántara ${ }^{33}$, acompañadas por el propio maestre, como bien recogen las diferentes crónicas: $e$ veose caminho dereito de Coimbra, e alli se jumtarom com elle o mestre de Santiago, e o mestre Dalcamtara, e as companhas Daadaluzia ${ }^{34}$. La incursión se saldó con la derrota militar portuguesa que tuvo su corolario en las paces de Santarem, marzo de 1373, cuyas disposiciones ponen claramente de manifiesto la victoria castellana que

\footnotetext{
${ }^{31}$ TORRES Y TAPIA, Crónica, t. II, p. 134.

${ }^{32}$ Ibídem, t. II, p. 134-135.

${ }^{33}$ P. LóPEz de Ayala, Crónica del Rey Don Enrique, p. 339 (Ed. G. Orduna, Crónica del Rey Don Pedro y del Rey Don Enrique, su hermano, hijos del rey don Alfonso Onceno, II, Madrid, 1997.

${ }^{34} \mathrm{~F}$. LOPES, CFI, cap. LXXII, p. 190. También López de Ayala hace referencia a la presencia del maestre de Alcántara (Crónica del Rey Don Enrique, p. 339).

«Anuario de Estudios Medievales», 34/1 (2004), pp.79-98 .- ISSN 0066-5061.
} 
se tradujo en la recuperación de sus fronteras: Valencia de Alcántara y las otras villas retornaban a manos castellanas ${ }^{35}$.

No sabemos mucho más de Ruy Díaz de la Vega, solamente que a su muerte el maestrazgo fue ocupado, a comienzos de 1376, por el ya citado Diego Martínez - mas aplaudidos son los que se dan después de grandes merecimientos, que los que antes anticipadamente ${ }^{36}$ - del que Torres y Tapia señala que fuen sin duda del linage y familia de los Maestres $D$. Gonzalo y $D$. Suero Martínez ${ }^{37}$. Tres años más tarde, en mayo de 1379 , moría el rey Enrique II, un rey del que podemos decir que fomentó cierto sentimiento "nacionalista" que se observa, entre otras cosas, en la utilización creciente de las fronteras como barrera de separación tajante entre reinos ${ }^{38}$. Quizás eso explique que a partir de su reinado no volvamos a ver lo que hemos venido llamando "indefinición" fronteriza, propia, hasta este momento, de las tierras alcantarinas y tampoco la "indefinición", cuando no el rechazo, de la Orden de Alcántara a la hora de apoyar a la corona castellana en sus disputas con Portugal. La Orden quedará definitivamente vinculada a la Corona, al pujante fortalecimiento del poder monárquico y a la búsqueda de las señas de identidad $^{39}$.

A Enrique II le sucedió en el trono su hijo, Juan I, que también tuvo en el enfrentamiento con Portugal el más importante de sus problemas, enfrentamiento que tuvo su colofón en la crisis, auténtica guerra de carácter nacional, acaecida entre 1383 y 1385. En todos estos conflictos la Orden de Alcántara desplegó, siempre al lado del monarca castellano, una importante actividad $^{40}$, a veces, como ya veremos, con un alto coste.

\footnotetext{
${ }^{35}$ No estamos muy seguros de que la vuelta de Valencia de Alcántara a manos castellanos sucediera de forma instantánea. Francisco de Rades, aunque sin citar exactamente el momento ya que solo dice que ocurrió durante el maestrazgo de Ruy Díaz de la Vega, cuenta que la villa estuvo durante mucho tiempo en manos de Fernando I de Portugal lo que avalaría la indefinición fronteriza y legal de estos territorios alcantarinos (Chronica de Alcántara, fol. 32).

${ }^{36}$ TORRES Y TAPIA, Crónica, t. II, p. 139.

${ }^{37}$ Ibídem.

${ }^{38} \mathrm{~J}$. VALDEÓN, La victoria de Enrique II: Los Trastámaras en el poder en "Génesis medieval del Estado Moderno: Castilla y Navarra (1250-1370)", 1987, p. 257.

${ }^{39}$ Ibidem, p. 256.

${ }^{40}$ Sobre la importancia de la Orden de Alcántara nos habla el cronista portugués Fernão Lopes: aquella frontartia he grossa de gentes e gramdes senhores, assi como do meestre de Samtiago e do meestre d'Alcantara. . (Crónica de D. João I de Fernão Lopes segundo o códice $n^{\circ}$ 352 do Arquivo Nacional da Torre do Tombo, vol. 1 (1983), pp. 16 y $20=$ LOPES, CJI

«Anuario de Estudios Medievales», 34/1 (2004), pp.79-98 .- ISSN 0066-5061.
} 
La insatisfacción de Fernando I por los resultados del tratado de Santarem ${ }^{41}$, unida a la creciente hegemonía peninsular de la corona castellana, están en el origen de la nueva confrontación entre los dos reinos. El detonador debemos buscarlo en el acuerdo, en julio de 1380, del monarca portugués con el duque de Láncaster que contemplaba la llegada de soldados ingleses a Portugal, cosa que ocurrió aproximadamente un año después, en el otoño de 1381, con el objeto de invadir Castilla. Estas primeras refriegas se saldaron con la victoria naval castellana en la localidad de Saltes, verano de 1381, y con diversas escaramuzas, en la zona de la actual Extremadura, que desembocaron en la paz que lleva el nombre de la ciudad fronteriza de Elvas, en agosto de 1382. En estos acontecimientos la Orden desplegó una actividad importante como recogen las diferentes crónicas cuando señalan la presencia del maestre de Alcántara en el frustrado asedio que el infante portugués D. Juan, al servicio de la corona castellana, hizo a la citada ciudad, entre julio y agosto de 1381, y en la toma del castillo de Almeida a finales del mismo mes de agosto: $O$ comde Dom Alvaro Perez de Castro estava en Elvas por fronteiro, segumdo ja teemdes ouvjdo, e o Iffante Dom Joham seu sobrinho, que amdava en Castella como o meestre de Samtiago Dom Fernanzadores e o meestre Dalcamtara ${ }^{42}$. También estuvieron presentes las milicias alcantarinas en las tierras extremeñas, concretamente en el margen del río Caya comtra Badalhouçe $e^{43}$, aunque en este caso no llegara producirse el enfrentamiento $^{44}$ yí, por el contrario, la ya citada paz de Elvas que fue firmada en agosto de $1382^{45}$. Entre las cuestiones tratadas desde luego ninguna se relacionaba con aspiraciones fronterizas portuguesas sobre territorios "alcantarinos".

\footnotetext{
${ }^{41}$ vingar a fronta do tratado de Santarém en palabras de J. VERÍSSIMO SERRÃo (História de Portugal [1080-1415], 2001, p. 291.

${ }^{42}$ F. LOPES, CFI, cap. CXXXI, p. 365.

${ }^{43}$ Ibídem, cap. CLIII, p. 423.

${ }^{44}$ En este punto hay diversidad de opiniones en cuanto a las razones de porque no entraron en combate los dos ejércitos. Para el cronista portugués Lopes la causa habría que buscarla en la actitud del ejército castellano: veemdo que el Rei de Castella non quería vijnr aa batalha, tornaromsse os Ingreses para seu arreal, e el Rei para Elvas com toda su campanha" (CFI, Cap.CLIII, p. 424). Para la historiografía moderna las razones son otras (L. SUÁREZ, Historia del reinado de Juan I de Castilla, t. I (1977), p. 115). Véase también de este mismo autor Juan I (1379-1390), 1994, p. 83 y ss.

${ }^{45}$ Sobre el tratado de paz y su significado ver las obras del profesor Suárez citadas en la nota anterior.
}

«Anuario de Estudios Medievales», 34/1 (2004), pp.79-98 .- ISSN 0066-5061. 
El casamiento del rey castellano con Beatriz, la única hija de Fernando I, y la muerte de este último sin otra descendencia desató una serie de acontecimientos que provocaron una guerra que algunos autores han calificado de "nacionalista" y "revolucionaria"46. En todos esos acontecimientos volvió a estar presente la Orden de Alcántara y su maestre, acompañando siempre al monarca castellano. Lo estuvo en la boda del rey con la infanta portuguesa el 13 de mayo de 1383 en la ciudad de Badajoz: E partió el Rei pera Badalhouçe, çidade de seu Regno açerqua do estremo, mujto acompanhado de pellados e fidallgos, e cijnha hi o Iffante Dom Fernandoseu filho......e Don Diego Martijnez, meestre Dalcamtara... ${ }^{47}$ y también lo estuvo en los diversos enfrentamientos militares que surgieron después de que Juan I adoptara el título de rey de Portugal y reclamara para su mujer el trono lusitano a lo que se opuso buena parte de la sociedad portuguesa, principalmente las capas populares y una buena parte de la burguesía, a cuya cabeza se encontraba el maestre de Avis y futuro rey de Portugal, don João.

En diciembre de 1383, se produjo la entrada de las tropas castellanas en Portugal sucediéndose las batallas, escaramuzas y asedios. Uno de los sucesos más importantes, no tanto por su importancia militar, sino por su valor "psicológico", fue la batalla dos Atoleiros que tuvo lugar el 6 de abril de 1384: E porque eu ei por novas çertas que o Prioll do espitall meu irmao, e o Meestre dAlcamtara e Joham Rodriguez de Castanheda, e outros senhores, con ssoma de gemtes estam ja no $\mathrm{Crato}^{48}$ que supuso una severa derrota para las tropas de Juan I, teniendo en la muerte del maestre alcantarino, Diego Gómez Barroso ${ }^{49}$, su hecho más significativo ${ }^{50}$. Más importante fue

\footnotetext{
${ }^{46} \mathrm{Han}$ sido numerosos los trabajos sobre la importancia y el significado de la crisis 1383 1385. Entre otros, merece destacarse las páginas que le dedica Veríssimo Serrão en su História de Portugal, pp. 298-309.

${ }^{47}$ LOPES, CFI, cap. CLXIII, p. 451.

${ }^{48}$ LOPES, $C J I$, p. 174

${ }^{49}$ Este maestre había sustituido a Diego Martínez, muerto a lo largo de 1383, sin que sepamos la fecha exacta aunque siempre con posterioridad a mayo de 1313, porque como hemos visto en esa fecha acompañaba al Rey a su boda.

${ }^{50}$ Señalan las Crónicas que además del Maestre fallecido, la Orden sufrió numerosas bajas: Entre los caualleros que en aquella batalla murieron, se halla memoria que fue vno don Martn Nieto, Clavero, y otro Frey Gonçalo de Deça, Comendador de Herrera, y otro Frey Juan de Lerina, Comendador de Beluis (RADES, Chronica Alcantara, fol. 32v). Por su parte, Torres y Tapia aunque niega la existencia de tales freires, señala que el Maestre y los que con el murieron fueron traidos al convento de Alcántara y les dieron Sepultura (Crónica, t. II, p. 151). Lopes señala que foi hi morto ho Meestre dAlcamtara y con él outros boos fidallgos que nom eran de tamanha comta (CJI, vol. I, p. 182) Por su parte López de Ayala, solamente señala la muerte del 
el frustrado asedio a Lisboa ${ }^{51}$ en el que encontramos al nuevo maestre de Alcántara, Gonzalo Núñez Guzmán ${ }^{52}$ : Volvió el maestre [después de su toma de posesión] a la Villa de Alcántara, convocó sus Comendadores, Caballeros y vasallos, y fue a cumplir el mandato del Rey y acompañarle en la entrada que hizo en aquel Reyno y asedio que puso sobre la ciudad de Lisboa ${ }^{53}$.

No tenemos constancia de la participación alcantarina en la batalla de $\operatorname{Trancoso}^{54}$, que tuvo lugar a principios de junio de 1385, pero sí, esta vez con éxito, acompañando, el mismo mes de junio, al rey Juan I en Mértola, donde los portugueses tenían cercado el castillo del mismo nombre que estaba defendido por un caballero portugués, de nombre Fernando Dantes, al servicio de la corona castellana ${ }^{55}$. También estuvo la Orden en la famosa y determinante batalla de Aljubarrota ${ }^{56}$ donde el maestre alcantarino ocupó un lugar protagonista en los acontecimientos encargándose de proteger la retirada de las tropas -E Don Gonzalo Núñez de Guzmán, maestre de Alcántara, estovo grand pieza con los de caballo en el campo que la batalla fue desbaratada ${ }^{57}$, lo que le supuso el maestrazgo de la Orden de Calatrava que estaba vacante desde la muerte, en la citada batalla de Aljubarrota, de su maestre Pedro Álvarez de Pereira: su sustituto en la milicia extremeña, el mismo año 1385 , fue el portugués y antiguo clavero de la Orden de Avis,

maestre de Alcántara (Crónica de rey don Juan I, de Castilla e de León, Crónica de los Reyes de Castilla, MARTín J.L. (ed.), 1991, p. 564= LÓPEZ DE AYALA, CJI.

${ }^{51}$ El profesor Suárez señala que el malogrado sitio a la ciudad de Lisboa fue más importante y decisivo que la famosa batalla de Aljubarrota (Historia del reinado de Juan I, t. I, p. 190).

${ }^{52} \mathrm{La}$ confirmación papal de su nombramiento se produjo el 16 de septiembre de 1384 , cuando Clemente VII certificó la legitimidad de su nombramiento (PALACIOS, Colección de Alcántara, I, doc. $\mathrm{n}^{\circ} 709$, p. 489), Las Crónicas nos dicen además que el nuevo maestre era hijo de Pedro Nuñez de Guzmán, señor de las villas de Vililla y Aviados, y que había sido comendador de Ceclavín (TORRES Y TAPIA, Crónica, t. II, p. 152).

${ }^{53}$ Ibídem, t. II, p. 152.

${ }^{54}$ Tanto el maestre de Alcántara, como los maestres de las otras órdenes, se encontraban en Córdoba acompañando al rey Juan I. Sobre la batalla y sus protagonistas S.M. Dias Arnaut nos proporciona importantes datos y comentarios (A batalha de Trancoso, Coimbra, 1947)

${ }^{55}$ TORRES Y TAPIA, Crónica, t. II, p. 154.

${ }^{56}$ Estava ganha a independencia nacional $e$, por tal motivo, nao admira que Aljubarrota tenha permanecido, ao longo dos séculos, como un marco decisivo da historia portuguesa VERÍSSIMO SERRÃO, Historia de Portugal, t. I, p. 312.

${ }^{57}$ LÓPEZ DE AYALA, CJI., pp. 598 y ss: Otras crónicas recogen también el papel relevante del maestre como la de TORRES Y TAPIA (Crónica, t. II, p. 155 y ss.) y RADES (Chronica de Alcántara, fol. 20 y ss.).

«Anuario de Estudios Medievales», 34/1 (2004), pp.79-98 .- ISSN 0066-5061. 
Martín Yañez de Barbudo ${ }^{58}$-sin que le obtase ser de Religion y Reyno estraño ${ }^{59}$ - quien hizo frente, junto a los maestres de Santiago y Calatrava, a la entrada portuguesa que tuvo lugar en el otoño del mismo año de 1385: Pretendía hacerse dueño y Señor de otras muchas [villas y lugares] de esta Corona que confinaban con las de la suy ${ }^{60}$. A partir de este momento y hasta la muerte del rey en el año 1390, seguiremos viendo a la Orden al lado de la monarquía castellana en cuantos episodios enfrentaron a los dos reinos, muchos de ellos relacionados con la presencia en tierras peninsulares del Duque de Láncaster ${ }^{61}$, y que tuvieron su final en las treguas de Monção del 29 de noviembre de 1387 y en el tratado de Bayona de julio de 1388.

El panorama de las relaciones entre la Orden de Alcántara y la Corona durante los primeros dos reinados de la dinastía Trastámara nos permite contemplar un cambio sustancial en las mismas con respecto a lo anterior. Vemos como la Orden, por un lado, pone fin a su dubitativa y equívoca, en el mejor de los casos, fidelidad castellana, jalonada de crisis y conflictos, como en el supuesto del maestre Melen Suárez y, por otro, es patente la disminución de su autonomía institucional que se refleja, como veremos más adelante, en el control de los nombramientos de cargos de la Orden por parte de los respectivos monarcas. Podemos decir, pues, que a partir de Enrique II

${ }^{58} \mathrm{El}$ rey Juan I lo había hecho también su Merino Mayor entre el Tajo y el Guadiana. No estamos seguro de su toma de posesión pero debió ser entre mayo y septiembre de 1385 , fecha esta última en la que aparece en la documentación pro primera vez como maestre (PALACIOS, Colección de Alcántara, I, doc. 718, pp. 499-502). Sobre las circunstancias y el significado de su muerte en 1394, ver el trabajo de C. DE AYALA, Ordenes militares y frontera en la Castilla del siglo XIV, "En la España Medieval", 23 (2000), pp. 279 y ss.

${ }^{59}$ Es significativo como apunta Torres y Tapia, el enorme malestar de la Orden por tal nombramiento: "No sintieron poco el Prior, Comendador Mayor y los demás Electores el empeño en que el Rey se había puesto y verse obligados a romper con las leyes de la suya" (Ibídem, t. II, p. 163).

${ }^{60}$ TORRES y TAPIA, Crónica, t. II, p. 167.

${ }^{61}$ Torres y Tapia recoge alguno de estos enfrentamientos en los que tuvo especial protagonismo el maestre alcantarino: en 1386, el maestre, acompañado según el cronista, del infante portugués D. Juan y del maestre de Santiago, García Fernández entrará en el reino de Portugal tomando la villa de Campo mayor, y poniendo a su frente a su primo Gil Vaez de Barbudo (Crónica, t. II, p. 168) que fue tenente de la ciudad hasta 1388, momento en que las tropas portuguesas, después de un largo asedio la devuelven a los dominios de la corona lusitana Ibídem, t. II, pp. 171-172. Otra incursión del maestre alcantarino en tierras portuguesas había tenido lugar en 1387, concretamente, según dice la Crónica, por la Provincia de la Vera y Castel Blanco (Ibidem, t. II, p. 169).

«Anuario de Estudios Medievales», 34/1 (2004), pp.79-98 . - ISSN 0066-5061. 
y de Juan I se produce la definitiva integración "nacional" de la Orden ${ }^{62}$ y de sus territorios dentro de la Corona castellana y de su "espacio soberano", proceso que tiene mucho que ver también con la mayor presencia de Extremadura en la Corte Castellana ${ }^{63}$ y que constituye, junto a otros, un elemento imprescindible en la edificación del "estado moderno". El final de este proceso, en lo relativo a las órdenes militares, es la "soberanización" de estas instituciones a través de la incorporación de sus maestrazgos a la Corona durante el reinado de los Reyes Católicos a finales del siglo XV.

\section{El CONTROL DEL NOMBRAMIENTO DEL CARGO DEL MAESTRE POR PARTE DE LA CORONA}

Ya nos hemos referido a como el instrumento más importante y más eficaz que tenía la Monarquía para control de las órdenes militares era el de su intervención, más o menos directa y casi siempre con un carácter coactivo, en la provisión y destitución de su más alto cargo, el de maestre. El proceso, que tenía sus antecedente más claros durante el reinado de Alfonso XI, tuvo su continuación con Pedro I ${ }^{64} \mathrm{y}$, como hemos podido constatar, prosiguió también con Enrique II.

Pero será durante el reinado de Juan I cuando se "legalice" la intervención real gracias a una concesión del papa Clemente VII, datada el 11 de julio de 1383, cuyo tenor establecía que si quedaran vacantes los maestrazgos de las órdenes de Santiago, Calatrava o Alcántara, el rey de Castilla podría nombrar directamente, aunque con ciertos condicionantes, a los nuevos maestres $^{65}$. Ese mismo día, el Papa ordenaba al arzobispo de Toledo que aceptara e hiciera cumplir con tal disposición ${ }^{66}$.

\footnotetext{
${ }^{62}$ No deja de ser significativa en este sentido la conducta de García Pirez, un freire portugués de la Orden de Alcántara, tenente del estratégico castillo de Marvao y que, como la Orden, continuó fiel a Juan I durante los acontecimientos que precedieron a la batalla de Aljubarrota (LOPES, CJI, p. 160).

${ }^{63}$ J.L. MARTín MARTín y Ma .D. GARCÍA OliVA, Historia de Extremadura, II, Los tiempos medievales, Mérida, Consejería de Educación y Cultura de la Junta de Extremadura, 1985, p. 375 y ss.

${ }^{64}$ Ver nuestro trabajo ya citado Los maestres de la Orden de Alcántara durante los reinados de Alfonso XI y Pedro I, p. 329 y ss.

${ }^{65}$ Palacios, Colección de Alcántara, I, doc. no 704, pp. 483-484.

${ }^{66}$ Ibídem, I, docs. n 705 y 706, pp. 484-487.
}

«Anuario de Estudios Medievales», 34/1 (2004), pp.79-98 .- ISSN 0066-5061. 
La medida papal debió encontrar resistencias, bien en la Iglesia, bien en la propia Orden, o bien en ambas, lo que explicaría un documento de 16 de septiembre de 1384 a través del cual Clemente VII legitimaba el nombramiento del maestre de Alcántara, don Gonzalo Núñez de Guzmán ${ }^{67}$. Un año después, el 21 de septiembre de 1384, el Papa tendría que reiterar la resolución al arzobispo de Toledo, comunicándosela también al de Sevilla, así como a los obispos de Burgos ${ }^{68}$ y Zamora, especificando en este último caso que el nombramiento se haría con la intervención del arzobispo de Toledo ${ }^{69}$.

No hace falta explicar la importancia que para la Monarquía tenía tal concesión, en cuanto que le iba a permitir la utilización de un instrumento tan importante para el control de las órdenes militares, no esperando ahora traba alguna, puesto que las precauciones y condicionantes que recogía la resolución fueron obviados la mayoría de las veces por parte de la Orden. Otro factor trascendental era que, con ella, se neutralizaban las posibles disensiones internas que podría provocar el nombramiento de un nuevo maestre: a los órganos colegiados, facultados hasta ese momento para elegir al nuevo maestre, no les quedaba más papel que refrendar la elección real. En este momento el Papa había abierto la puerta a la intervención legítima de los reyes y con ello, despejaba, como dice Carlos de Ayala, el camino a la incorporacióin de los maestrazgos a la Corona ${ }^{70}$.

\section{LAS DONACIONES REALES A LA ORDEN}

No hemos encontrado en la documentación ninguna donación a la Orden efectuada por la Corona, lo que no es extraño porque, ya desde mediados del siglo $\mathrm{XIV}^{71}$, se había puesto fin al proceso de acumulación territorial, dotando a la Orden de unos contornos "geográficos" que perseverarán casi íntegramente hasta finales del siglo $\mathrm{XV}$.

Un cambio notable en el mapa alcantarino y el único caso que tenemos del interés de la Corona por su patrimonio, fue la permuta realizada

${ }^{67}$ Ibídem, I, doc. $\mathrm{n}^{0} 709$, p. 489-490.

${ }^{68} \mathrm{Ibi}$ dem, I, doc. $\mathrm{n}^{\circ} 711$, p. 492.

${ }^{69}$ Ibídem, I, doc. $\mathrm{n}^{\mathrm{0}} 710$, pp. 490-492.

${ }^{70}$ Las órdenes militares hispánicas, p. 737.

${ }^{71}$ Novoa PoRTEla, La Orden de Alcántara y Extremadura, p. 95 y ss.

«Anuario de Estudios Medievales», 34/1 (2004), pp.79-98 .- ISSN 0066-5061. 
por la Orden el 24 de mayo de 1378 con el propio rey don Enrique. La Orden entregaba la villa y castillo de Morón, junto con la fortaleza de Cote por los lugares de Ginés y de la Barra de Algava, además de otra serie de bienes y heredades, entre ellos, el lugar de Collera, situados todos ellos en Sevilla, con el objetivo de que la Orden formara dos encomiendas ${ }^{72}$. No sabemos ciertamente las razones últimas de la permuta, pero todo parece indicar que éstas estuvieron relacionadas con la intención de mejorar la repoblación de la zona y con una creciente preocupación del rey por la eficacia militar castellana en la frontera con Granada, hipótesis que parece ratificar el documento de permuta cuando dice: las villas et castillos fuertes de los nuestros sennorios de las fronteras de los reynos estrannos, et especialmente de los nuestros enemigos de la fe, non pueden estar nin están tan bien aperçibidos para defendimiento de los nuestros reynos et de la Cristiandad commo quando están so sennorío et en poder de los reyes e de los prinçipes e sennores ${ }^{73}$. En cualquier caso, solamente unos meses después, antes de mayo de 1379, Morón y Cote están en poder de don Enrique Enríquez, hijo bastardo del Rey, que las tuvo en su poder hasta principios de 1385 en que vuelven a la $\operatorname{Orden}^{74}$.

\section{LA CONFIRMACIÓN DEL PATRIMONIO DE LA ORDEN POR LA CORONA}

Otro de los instrumentos importantes que tenían los monarcas en su poder para el control de las órdenes militares era la confirmación de sus privilegios y de su patrimonio, ya que, por un lado, mostraba su disposición hacia las órdenes y, por el otro, la confirmación tenía el propósito de ganarse la confianza de estas instituciones, sobre todo en aquellos momentos en que su participación era más necesaria para la Corona. Es el caso de las confirmaciones que hace Enrique II durante la guerra civil: en febrero de 1367, dos meses antes de la batalla de Nájera, el futuro monarca, confirmaba al maestre

\footnotetext{
${ }^{72}$ Palacios, Colección de Alcántara, I, doc. nº 694, pp. 473-479.

${ }^{73}$ Ibídem, p. 474

${ }^{74}$ Ver el trabajo de M. GARCía FERNÁNDEZ, Morón de la Frontera y Enrique II. Los privilegios reales de 1378 en "Archivo Hispalense", 227 (1991), pp.4-25. Desconocemos el destino de Ginés, de la Barra de Algava y demás posesiones, de las que, por otra parte, no tenemos constancia en la documentación alcantarina.

«Anuario de Estudios Medievales», 34/1 (2004), pp.79-98 .- ISSN 0066-5061.
} 
enriquista Pedro Muñiz de Godoy un privilegio de exención a favor de la villa alcantarina de $\mathrm{Gata}^{75}$. Solamente cuatro días más tarde, en las Cortes celebradas en Burgos, y a petición del entonces clavero, Melen Suárez, Enrique II confirmaba, esta vez, una serie de privilegios otorgados por Alfonso XI en la cortes de Valladolid de $1326^{76}$. El mismo carácter tenía la confirmación, solicitada por un comendador alcantarino de nombre Sancho Gutiérrez, de la concesión de una renta anual de $3840 \mathrm{mrs}$ a percibir en la martiniega de Ciudad Rodrigo que había sido realizada por Alfonso $\mathrm{XI}^{77}$.

Pero, además de estas confirmaciones puntuales, hubo otras ratificaciones que tenían un carácter "general" y que se realizaban normalmente al inicio de cada uno de los maestrazgos, como la efectuada por Juan I, concretamente en agosto de 1379 , en la que confirmaba al maestre Diego Martínez los privilegios concedidos a la milicia extremeña por todos sus antepasados $^{78}$. Ese mismo año, en junio, la confirmación al comendador d'Alcántara, de Castela de todos los bienes de la Orden en Valellas y el Pereiro por parte del rey Fernando I de Portugal ${ }^{79}$ constituye un ejemplo de equilibrio "diplomático" de la milicia extremeña.

\section{CONCLUSIONES}

La más importante de las conclusiones de este trabajo, la constituye el hecho de que durante los reinados de Enrique II y Juan I, principalmente este último, la Orden de Alcántara sufrirá un proceso de "nacionalización" que pondrá fin a su hasta entonces ambigua lealtad política. No es ajeno este proceso a la política general de los primeros trastámaras, que podemos caracterizar por un fortalecimiento del poder monárquico que se tradujo, entre otras cosas, en el uso progresivo de las fronteras como barrera de separación terminante entre reinos - la soberanización del territorio- y en relación con las órdenes militares, en un fuerte y constante intervencionismo, principalmente a través del control del nombramiento de los nuevos maestres. En

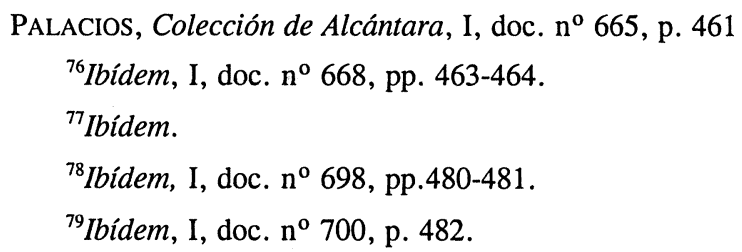


relación con esto último, fue determinante la bula de Clemente VII, datada en 1383, que permitía al rey Juan I intervenir "legalmente" en el nombramiento de los maestres de Alcántara, Calatrava y Santiago y que supuso, a la postre, una puerta abierta a la integración de los maestrazgos en la Corona. El control de la Orden se llevó a cabo, además, gracias a instrumentos legales como la confirmación de las posesiones de la milicia extremeña. 